
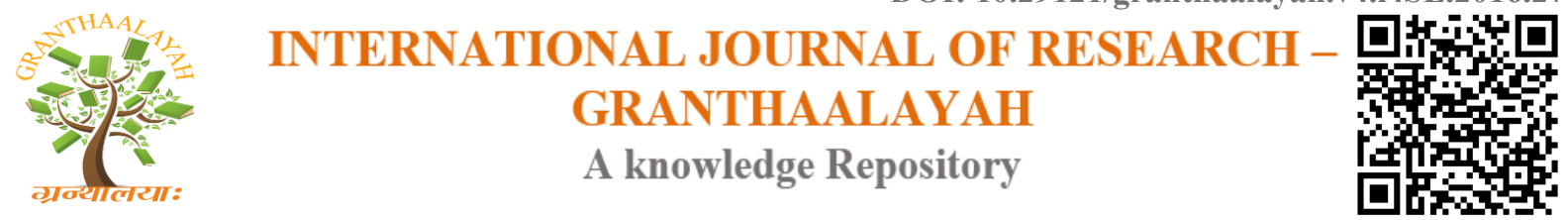

Management

\title{
MEDIA AND WOMEN HEALTH IN INDIA
}

\author{
K. Parkavi ${ }^{* 1}$ \\ ${ }^{*}$ Ph.d Research Scholar, Department of Mass Communication, Mother Teresa University, \\ Kodaikanal, INDIA
}

\begin{abstract}
Health Communication is an important domain in communication arena aims at disseminating health messages to the public. In this study the role of media in giving health information to women is analysed. The portrayal of women in media, the impact it creates on the minds of women, both urban and rural background is scrutinised separately. The responsibility of media in the rural health of women is critically studied and media's role in Idealising body images in the mind of urban women is also analysed.
\end{abstract}

Keywords:

Women health, Media role, Stereo typing, Body images.

Cite This Article: K. Parkavi, "MEDIA AND WOMEN HEALTH IN INDIA" International Journal of Research - Granthaalayah, Vol. 4, No. 4: SE (2016): 41-44.

\section{INTRODUCTION}

Media plays a vital role in the dissemination of information. It is called the fourth pillar of democratic polity. The role of media is not only limited as information providers, but by gradually shaping public opinion, personal beliefs and even people's self-perception, media influences the process of socialization and shapes ideology and thinking also. Health communication links the domains of communication and health and is increasingly recognized as a necessary element of efforts to improve personal and public health. Lack of health information and education is the main barrier in achieving better health status.

\section{OBJECTIVE OF THE STUDY}

In order to gain a shared understanding of the condition of the health status of women in India and the role of media in creating awareness about their health issues, this document surveys papers done by scholars in women health and the media role in the existing arena of women health.

The areas discussed in this paper are,

$>$ Portrayal of women in media

$>$ The health status of rural women and media's role in women health in India. 
$>$ Media and Urban women's health

\section{PORTRAYAL OF WOMEN IN MEDIA}

Over the years and especially during the last decade, India has developed a fairly extensive communication infrastructure. The subject of portrayal of women in Indian media has drawn the attention of media critiques in the present times. Women have been portrayed as men would like to see them beautiful creatures, submissive mothers of their children, efficient housekeepers etc. Women's image has gone through several unjust projections at the hands of media.

The Indian television programmes on women are based on the lives and cultures of urban society. In quantity there have been very few, in quality very poor. No programme is concerned with the problems of women in rural areas. The main reason behind this is the commercial nature of Doordarshan or any other private channels. Commercial sponsors and advertisers do not prefer women issue programmes, which they think are not very popular and or not liked by majority audience (Dhar, pattanik, 1996). Indian magazines contain primarily and predominantly volumes of advertisements and sexist writings. According to Guru (1996), vast majority of Indian magazines are known for the portrayal of women as sex objects, consumers and slaves. In today's media women are looked upon as a tool that can help to sell a product. Women and sex are often a great combination when to get a product to come off the shelves. There are many different companies that stretch far and wide to include women and sex in their advertisements.

\section{HEALTH STATUS OF WOMEN IN INDIA AND MEDIA}

India is one of the few countries in the world, where women and men have nearly the same life expectancy at birth (kilbourne, 1990). Recently there is a great decline in the sex ratio in India. The most extreme expressions of the preference for sons are female infanticide and sex selective abortions. Apart from that, women are prone to many life threatening diseases, but they get less health care than men even as children. Poor health has repercussions not only for women but also their families. Women in poor health are more likely to give birth to low weight infants. They are also less likely to be able to provide food and adequate care for their children.

Unwanted pregnancies terminated by unsafe abortions also have negative consequences for women's health. The high levels of maternal mortality are especially distressing, because the majority of these deaths could be prevented if women had adequate knowledge about health services either proper prenatal care or referral to appropriate health care facilities (jejeebhoy and Rao 1995). In fact the leading contributor to high maternal mortality ratios is lack of access to health care (The world bank 1996). Studies have found that twenty percent of all maternal deaths in india is caused by anemia (The world bank 1996).

Women do not even have the knowledge about anemia a simple reason for death which can easily be avoided if they get the knowledge. India has the highest incidence of cervical cancer in the world which could be reduced by a simple papsmear test. News reports say that female infanticide has reached the one crore mark in the last decade in India. And everybody knows that hundreds of women are killed every year on every front and every imaginable pretext. If this trend continues there is possibility of women becoming an extinct species. 
Despite the alarming growth of the epidemic AIDS, most women in India have little knowledge of AIDS. The NFHS found that a large majority of Indian women had never heard of AIDS. There were many misconceptions among those who had heard of the disease.

"Health information is the most important resource in health care and health promotion, because it is essential in guiding strategic health behaviors, treatments and decisions" (kreps, 1988). But Indian media's role in creating health awareness among women in India is very minimal. Apart from some government funded programmes on AIDS, contraceptives and immunizations, media's commercial face had not allowed them to care about women's health in India.

\section{MEDIA IMPACT ON URBAN WOMEN AND THEIR HEALTH STATUS}

When there is a lack of knowledge about their basic health in rural areas among women and media not doing any role in giving health literacy or awareness, in urban areas the stereo typing of women and body image distortation shows media has no concern about the health of women altogether.

As media images glamorizing the extremely thin continue to rule newspaper and magazine covers, an increased number of women are becoming worried over their bodies and therefore engaging in unhealthy eating behaviors such as excessive dieting. They are running behind any weight reducing technique, through tablets or imported machines, fascinated by the "Reduce 20 kgs in 10 days" type of advertisements.

Most of the television commercials are aimed at women being the main consumers. All advertisements compel women to worry about their hair, skin, complexion, body sizes etc. One advertisement talks like "Being fair" is the only solution to all women's problems. Starting from teen age girl to middle aged women in urban areas all women are conscious about their skin and body structure. In short Indian media's aim is to create beauty awareness among women rather than health awareness.

By promoting the ideal difficult to achieve and maintain the cosmetic and diet product industries are assured of growth and profit. The media's effect on women is troubling because it creates major body dissatisfaction in women which leads to low self-esteem, depression, obesity and eating disorders such as bulimia. The tragedy is many women internalize these stereotypes and judge themselves by the beauty industry's standards.

Thus the role and responsibility of media in Rural women's health is completely absent whereas the mental health of urban women is affected by their stereotyping body images.

\section{CONCLUSION}

Women health is the basis of any society. There can be development in any sphere, politics, economics, and science and so on.., but nothing can be achieved when the core of the society, women's health is neglected. The health of the future generation depends on the health of present women. So this is not a feminine problem, it's a social problem. And media should take the 
responsibility and real concern over women by looking into their health rather than their skin and beauty.

\section{REFERENCES}

[1] Jejeebhoy, shireen. J and sowmya Rama rao, 1995,"Unsafe motherhood: A review of reproductive health" monica das gupta and T.n.krishnan eds, Bombay.

[2] Heise, lori.l, 1994, violence against women the hidden health burden, World Bank discussion papers 255, Washington, $d c$.

[3] Women's health in India, Victoria A velkott and arjun alakha, International programs centre.

[4] Kreps, G.L. (1988) The pervasive role of information in health care; Implication for health communication policy, J.Anderson (ed) communication year book, newbury park, CA,sage. 5. www.harvard health publications.html

[5] www.concern.net

[6] AIDS Analysis, 1996, "India, a rapid and extensive spread of HIV', Incorporating AIDS and Society,vol.2,no.5,p.11 8.Anand,Meenu(2006) commodification of women The Irony;" Women's watch"vol.3, issue 3, April- Jjune 2006.NFIW. 